\title{
Performance Research on Slag-Steel Slag Based Composite Portland Cement
}

\author{
Xiaowei Sun ${ }^{1, a^{*}, \text { Wanyang Niu }}{ }^{1, b}$,Jingbo Zhao ${ }^{1, \mathrm{c}}$ \\ ${ }^{1}$ School of Materials science and Engineering, Shenyang Jianzhu University, China 110168 \\ axiaowei_sun11110@sina.com, ${ }^{b}$ niuwanyang@sjzu.edu.cn, ${ }^{c}$ zhaojinbo@sjzu.edu.cn
}

Keywords: composite Portland cement, steel slag, slag, activator

Abstract. Using slag, steel slag and Portland cement as the raw material with a small amount of activator, the composite Portland cement of magnitude 42.5R was prepared. The steel slag fineness, the composite ratio of slag-steel slag and the types of activator on the properties of composite Portland cement were studied in the research. The hydrated products of composite Portland cement and the micro-structure of harden cement paste were analyzed by SEM.

The results show that the greater the specific surface area of steel slag is, the shorter the setting time, and the higher the mortar strength will be. The cement setting time is prolonged, the expansion rate is increased and the mortar strength is decreased with the increase of the percentage of steel slag in composite Portland cement. The activity of slag and steel-slag is increased, the setting time is shortened and the mortar strength of each age is significantly increased with the adding of alkaline activator to composite Portland cement. Besides, SEM photos show that adding sodium silicate makes the cement hydration accelerated, C-S-H gel and - crystal continuously formed, the bonding degree of cement and aggregate increased, the gap of cement paste decreased and filled with hydration products.

\section{Introduction}

Along with the vigorous development of China's iron and steel industry, tens of millions of tons of waste residues are produced each year. The utilization ratio of waste residue is low in China, and the accumulation of large amount of waste residues not only occupies cultivable land, but also causes environmental pollution[1,2]. The granulated blast furnace slag and steel slag are waste residues produced by pig iron smelting in iron and steel production enterprises. Slag and steel slag are potential cementitious components of cement because of their similar chemical composition compared with that of cement clinker. Slag and steel slag can be used as auxiliary material in cement production and that can improve the performance of cement, broaden the cement product types, reduce the cost of production and bring more income for iron and steel production enterprises[3,4].

Liaoning province is one of Chinese traditional industrial bases and has many large iron and steel production enterprises such as Anshan Iron and Steel Group, Lingyuan Iron and Steel Group, Fushun Special Steel Company, and so forth. A large amount of slag and steel slag are produced and discharged from these enterprises every year. In order to make better use of these resources while taking into consideration of the actual cement production enterprises in Liaoning area, slag and steel slag were used as admixture and grinded it into fine powder. Composite Portland cement was prepared using this powder mixed with Portland cement and a small amount of activator. Then the fineness of steel slag, the composite ratio of slag and steel slag, and the types of activator effect on the properties of composite Portland cement were mainly studied in the paper. The aim of these studies was to seek the optimal proportion and composition of the composite Portland cement and achieve the goal of energy saving, emission reduction and waste recycling.

\section{Materials and Methods}

Materials. Slag: Water extracted blast furnace slag. After drying and grinding, Blaine specific surface area of the slag was $(400 \pm 10) \mathrm{m}^{2} \cdot \mathrm{kg}^{-1}$, density $2.80 \mathrm{~g} / \mathrm{cm}^{3}$, activity coefficient 0.30 , alkaline coefficient 1.04, mass coefficient 1.64. Its chemical composition was shown in Table 1. 
Tab 1 Chemical composition of slag/ \%

\begin{tabular}{cccccc}
\hline $\mathrm{SiO}_{2}$ & $\mathrm{Al}_{2} \mathrm{O}_{3}$ & $\mathrm{Fe}_{2} \mathrm{O}_{3}$ & $\mathrm{CaO}$ & $\mathrm{MgO}$ & $\mathrm{TiO}_{2}$ \\
\hline 36.65 & 10.89 & 2.04 & 40.81 & 8.70 & 0.21 \\
\hline
\end{tabular}

Cement: Portland cement of magnitude 52.5. The density of the cement was $3.06 \mathrm{~g} / \mathrm{cm}^{3}$, Blaine specific surface area $330 \mathrm{~m}^{2} \cdot \mathrm{kg}^{-1}$. Its chemical composition was shown in Table 2 . The mineral composition, ratio values and strength were shown in Table 3.

$\mathrm{Tab} 2$ Chemical composition of Portland cement / \%

\begin{tabular}{ccccccccc}
\hline $\mathrm{SiO}_{2}$ & $\mathrm{Al}_{2} \mathrm{O}_{3}$ & $\mathrm{Fe}_{2} \mathrm{O}_{3}$ & $\mathrm{CaO}$ & $\mathrm{MgO}$ & $\mathrm{TiO}_{2}$ & $\mathrm{R}_{2} \mathrm{O}$ & $\mathrm{MnO}$ & $\mathrm{SO}_{3}$ \\
\hline 20.49 & 7.53 & 4.72 & 62.13 & 1.98 & 0.09 & 0.75 & 0.05 & 0.88 \\
\hline
\end{tabular}

Tab 3 Mineral composition, ratio values and strength of Portland cement

\begin{tabular}{ccccccccccc}
\hline \multicolumn{3}{c}{ Mineral composition $/ \%$} & \multicolumn{2}{c}{ Ratio value/\% } & \multicolumn{2}{c}{$\begin{array}{c}\text { Flexural } \\
\text { strength/ }\end{array}$} & \multicolumn{2}{c}{$\begin{array}{c}\text { Compressive } \\
\text { strength/ MPa }\end{array}$} \\
\hline $\mathrm{C}_{3} \mathrm{~S}$ & $\mathrm{C}_{2} \mathrm{~S}$ & $\mathrm{C}_{4} \mathrm{AF}$ & $\mathrm{C}_{3} \mathrm{~A}$ & $\mathrm{KH}$ & $\mathrm{N}$ & $\mathrm{P}$ & $3 \mathrm{~d}$ & $28 \mathrm{~d}$ & $3 \mathrm{~d}$ & $28 \mathrm{~d}$ \\
\hline 31.6 & 35.0 & 12.0 & 14.4 & 0.84 & 1.67 & 1.59 & 5.4 & 8.1 & 24.6 & 52.6 \\
\hline
\end{tabular}

Steel slag(SS): steel slag of iron removal by magnetic separation. The density of the steel slag was $3.41 \mathrm{~g} / \mathrm{cm}^{3}$, alkalinity 1.90 (intermediate alkalinity). Its chemical composition was shown in Table 4.

Tab 4 Chemical composition of steel slag / \%

\begin{tabular}{ccccccc}
\hline $\mathrm{SiO}_{2}$ & $\mathrm{Al}_{2} \mathrm{O}_{3}$ & $\mathrm{Fe}_{2} \mathrm{O}_{3}$ & $\mathrm{CaO}$ & $\mathrm{MgO}$ & $\mathrm{P}_{2} \mathrm{O}_{5}$ & Loss \\
\hline 19.43 & 3.08 & 13.20 & 40.02 & 10.52 & 1.64 & 11.89 \\
\hline
\end{tabular}

Activator: pure chemical reagent..

Methods. The standard consistency, setting time and soundness were tested in accordance with Chinese standard titled Test Methods for Water Requirement of Normal Consistency, Setting Time and Soundness of The Portland Cement (GB/T 1346-2001). The mortar strength was tested based on Chinese standard titled Method of Cements-Determination of Strength (GB/T 17671-1999).

The hydration products of composite Portland cement and microstructure of harden paste were analyzed by SEM.

\section{Test Results and Discussion}

The effect of steel slag fineness on physical properties of the composite Portland cement. According to Chinese standard titled Steel Slag Powder Used for Cement and Concrete $(\mathrm{GB} / \mathrm{T}$ 20491-2006), the specific surface area of steel slag powder should not be less than $400 \mathrm{~m}^{2} \cdot \mathrm{kg}^{-1}$. The steel slag powders of the specific surface areas of $400 \mathrm{~m}^{2} \cdot \mathrm{kg}^{-1}, 430 \mathrm{~m}^{2} \cdot \mathrm{kg}^{-1}, 460 \mathrm{~m}^{2} \cdot \mathrm{kg}^{-1}$ were selected for the tests. The slag and steel slag were evenly mixed with mineral powder in the ratio of 1:1. Then the composite Portland cement was prepared which $50 \%$ of Portland cement was substituted by the mixture. The physical properties of composite Portland cement were shown in Table 5.

Tab 5 The physical properties of composite Portland cement

\begin{tabular}{|c|c|c|c|c|c|c|c|c|c|}
\hline \multirow[t]{2}{*}{ Sample } & \multirow{2}{*}{$\begin{array}{l}\text { Specific } \\
\text { surface } \\
\text { area of } \\
\mathrm{SS} / \\
\mathrm{m}^{2} \cdot \mathrm{kg}^{-1} \\
\end{array}$} & \multirow{2}{*}{$\begin{array}{c}\text { Standard } \\
\text { consistency } \\
\quad / \%\end{array}$} & \multicolumn{2}{|c|}{$\begin{array}{l}\text { Setting time } \\
/ / \mathrm{min}\end{array}$} & \multirow[t]{2}{*}{ Soundness } & \multicolumn{2}{|c|}{$\begin{array}{c}\text { Flexural } \\
\text { strength } \\
/ \mathrm{MPa}\end{array}$} & \multicolumn{2}{|c|}{$\begin{array}{c}\text { Compressive } \\
\text { strength } \\
/ \mathrm{MPa}\end{array}$} \\
\hline & & & Initial & Final & & $3 d$ & $28 d$ & $3 d$ & $28 \mathrm{~d}$ \\
\hline S400 & 400 & 26.1 & 204 & 321 & & 3.2 & 5.7 & 13.7 & 36.0 \\
\hline $\mathrm{S} 430$ & 430 & 25.8 & 186 & 278 & Qualified & 3.5 & 6.0 & 15.4 & 39.7 \\
\hline $\mathrm{S} 460$ & 460 & 25.3 & 172 & 267 & & 3.9 & 6.9 & 16.3 & 43.1 \\
\hline
\end{tabular}

Something could be seen from the experimental data of Table 5. In the composite system of slag and steel slag, the mortar strength of composite Portland cement became larger with the increase of specific surface area of steel slag powder, and the compressive strength was obviously increased among them. Compared with sample S400, the 3 days compressive strengths of samples S430 and S460 increased by $12.4 \% \sim 19.0 \%$, and those of 28 days increased by $10.3 \% \sim 19.7 \%$. This meant that the larger the 
differential specific surface area of steel slag powder, the higher activity of steel slag, and the better strength of composite Portland cement. But it could also be seen from the data that the early strength of composite Portland cement was greatly decreased with the incorporation of slag and steel slag compared to that of Portland cement (5.4 MPa /24.6 MPa). Even for the highest strength of sample $\mathrm{S} 460$, the 3 days flexural and compressive strength was only $3.9 \mathrm{MPa}$ and $16.3 \mathrm{MPa}$ which reduced by $27.8 \%$ and $33.7 \%$, respectively. The main reason was the formation temperature of slag and steel slag was generally above $1500{ }^{\circ} \mathrm{C}$, the main mineral of steel slag was tricalcium silicate and dicalcium silicate and they could crystallize more tightly. And the main mineral of slag was glasslike solid which was in the metastable state. The early hydration rate of slag and steel slag was slow and the early strength of composite Portland cement was also low. The slag and steel slag just played the role of particulate filling in gel system[5,6]. With the cement hydration and age extension, higher alkalinity steel slag released $\mathrm{Ca}(\mathrm{OH})_{2}$ which made the alkalinity of the liquid phase increased. Under this condition, both the disintegration rate of slag glass and the hydration process accelerated, the gels of hydrated calcium silicate and hydrated calcium aluminate gradually generated and later strength of the composite Portland cement was guaranteed.

The soundness of composite Portland cement was qualified. The standard consistency of the composite cement reduced and the setting time shortened with the increase of steel slag specific surface area. This was because the activity of steel slag increased after fine grinding and the hydration rate was relatively more quickly, then the rate which composite cement paste formed spatial mesh structure increased and that resulted in shortened setting time.

The effect of compound ratios of slag and steel slag on physical properties of the composite Portland cement. The steel slag powder of specific surface area $460 \mathrm{~m}^{2} / \mathrm{kg}$ was selected in the tests. The total dosage of slag and steel slag in the composite Portland cement was fixed at $50 \%$. The different samples of the composite Portland cement were prepared by adjusting the mass ratio. With reference to relative standards, the effect of different composite ratios of slag and steel slag on physical properties of the composite Portland cement was studied. The experimental data were shown in Table 6.

Tab 6 The physical properties of cements with different composite ratios of slag and steel slag

\begin{tabular}{|c|c|c|c|c|c|c|c|c|c|}
\hline \multicolumn{2}{|c|}{$\begin{array}{l}\text { Ratio } \\
/ \%\end{array}$} & \multirow[t]{2}{*}{$\begin{array}{l}\text { Standard } \\
\text { consistency } \\
\quad / \%\end{array}$} & \multicolumn{2}{|c|}{$\begin{array}{l}\text { Setting time } \\
/ \mathrm{min}\end{array}$} & \multirow[t]{2}{*}{$\begin{array}{l}\text { Soundness } \\
\text { /mm }\end{array}$} & \multicolumn{2}{|c|}{$\begin{array}{c}\text { Flexural } \\
\text { strength } \\
/ \mathrm{MPa}\end{array}$} & \multicolumn{2}{|c|}{$\begin{array}{c}\text { Compressive } \\
\text { strength } \\
/ \mathrm{MPa}\end{array}$} \\
\hline Slag & SS & & Initial & Final & & $3 d$ & $28 \mathrm{~d}$ & $3 d$ & $28 \mathrm{~d}$ \\
\hline 5 & 45 & 26.1 & 203 & 298 & 2.6 & 2.9 & 5.4 & 14.6 & 39.6 \\
\hline 15 & 35 & 25.6 & 186 & 276 & 2.1 & 3.7 & 6.5 & 15.6 & 42.7 \\
\hline 25 & 25 & 25.3 & 172 & 267 & 1.9 & 3.9 & 6.9 & 16.3 & 43.1 \\
\hline 35 & 15 & 25.4 & 146 & 243 & 1.6 & 4.2 & 7.2 & 16.5 & 44.1 \\
\hline 45 & 5 & 24.6 & 133 & 219 & 1.4 & 4.5 & 7.5 & 16.7 & 45.8 \\
\hline
\end{tabular}

The experimental data showed that the setting time prolonged with the increase of the steel slag percentage. The reason was the components of active silicon-aluminum in steel slag was less than that in slag and hydration rate was slow which led to less products of early hydration. Thus the setting time was prolonged.

The concentration of $\mathrm{f}-\mathrm{CaO}$ was higher in steel slag, then the incorporation of steel slag could cause cement paste expanded. The expansion rate gradually increased with the increase of steel slag dosage. The composite Portland cement was tested by Rayleigh clamp method and measured up to the national standards.

The mortar strengths of each age showed a gradually declined trend with the increase of steel slag dosage. This was mainly because the content of iron oxide in the steel slag was higher (13.20\%) and including some FeO-like impurities which made it more difficult to participate in the hydration. In addition, a small amount of $\mathrm{P}_{2} \mathrm{O}_{5}$ was contained in steel slag. The element $\mathrm{P}$ could make tricalcium silicates and dicalcium silicates in Portland cement and steel slag produce some decomposition and that reduced the cement mortar strength. When the mass ratio of slag and steel slag was 25:25 and 15:35, 
the mortar strengths of cement for ages of 3 days and 28 days could meet the need of the grade 42.5 composite Portland cement. The price of one ton of steel slag was 20 yuan cheaper than that of slag. Under consideration of the economic factors, the ratio of slag to steel slag was determined 15:35 in the tests.

The effect of activator types on physical properties of the composite Portland cement. Slag and steel slag were potential hydraulic admixture. Its hydration rate and the early strength were low due to its own reasons. The activity of steel slag could be chemically stimulated by an activator when they were used as cement-based material. Then its hydration rate could be speeded up and its activity could be increased. Three commonly used alkaline activators (sodium sulfate, sodium silicate and sodium hydroxide) were selected for study in the tests to screen the optimum activator which perform excellently and could meet to the requirement of the composite Portland cement standard. The ratios of the cement were like these: steel slag $35 \%$, slag $15 \%$, Portland cement $48 \%$ and activator $2 \%$. The experimental data were shown in Table 7.

$\mathrm{Tab} 7 \mathrm{The}$ effects of the activator on physical properties of composite Portland cement

\begin{tabular}{|c|c|c|c|c|c|c|c|c|c|}
\hline \multirow[t]{2}{*}{ Sample } & \multirow[t]{2}{*}{ Activator } & \multirow[t]{2}{*}{$\begin{array}{c}\text { Standard } \\
\text { consistency } \\
\quad / \%\end{array}$} & \multicolumn{2}{|c|}{$\begin{array}{l}\text { Setting time } \\
/ \mathrm{min}\end{array}$} & \multirow[t]{2}{*}{ Soundness } & \multicolumn{2}{|c|}{$\begin{array}{l}\text { Flexural } \\
\text { strength } \\
/ \mathrm{MPa}\end{array}$} & \multicolumn{2}{|c|}{$\begin{array}{c}\text { Compressive } \\
\text { strength } \\
/ \mathrm{MPa}\end{array}$} \\
\hline & & & Initial & Final & & $3 d$ & $28 d$ & $3 d$ & $28 d$ \\
\hline SN0 & --- & 25.6 & 186 & 276 & \multirow{4}{*}{ Qualified } & 3.7 & 6.5 & 15.6 & 42.7 \\
\hline SN1 & $\mathrm{Na}_{2} \mathrm{SO}_{4}$ & 25.4 & 168 & 251 & & 4.2 & 7.0 & 18.5 & 43.8 \\
\hline SN2 & $\mathrm{Na}_{2} \mathrm{SiO}_{3}$ & 24.8 & 154 & 243 & & 4.5 & 7.3 & 19.2 & 44.6 \\
\hline SN3 & $\mathrm{NaOH}$ & 25.2 & 163 & 246 & & 4.0 & 6.9 & 18.6 & 44.3 \\
\hline
\end{tabular}

By analyzing the data in Table 7, the standard consistency of the composite Portland cement changed a little, its soundness could meet the requirement and the setting time shortened in different degrees. Adding sodium silicate could get the most obvious effect which the initial setting time shortened 32 minutes and the final setting time shortened 33 minutes. Three types of alkaline activators improved the 3 days flexural and compressive strength of the composite Portland cement in different degrees. Compared with the cement without activator adding, the 3 days flexural strength of sodium silicate-adding cement increased by $21.6 \%$ (from $3.7 \mathrm{MPa}$ upto $4.5 \mathrm{MPa}$ ) while its $3 \mathrm{~d}$ compressive strength increased by $23.1 \%$ (from $15.6 \mathrm{MPa}$ upto $19.2 \mathrm{MPa}$ ). It was showed that using sodium silicate as an activator could significantly speed up the early cement hydration, stimulate the activity of slag and steel slag and that accelerated the hydration reaction of the cementitious system. Thus the 3 days mortar strength of the composite Portland cement could be improved. The 28 days cement flexural strength was $7.3 \mathrm{MPa}$, and the 28 days compressive strength was $44.6 \mathrm{MPa}$ and that could meet the requirement of grade $42.5 \mathrm{R}(4.0 \mathrm{MPa} / 19.0 \mathrm{MPa})$ for the composite Portland cement.

The analysis of microstructure and hydration products. The microstructure and hydration products of sample SN2 at 3 days were analyzed by using scanning electron microscope (FUJIFILM S4800). The results were as shown in Figure 1.

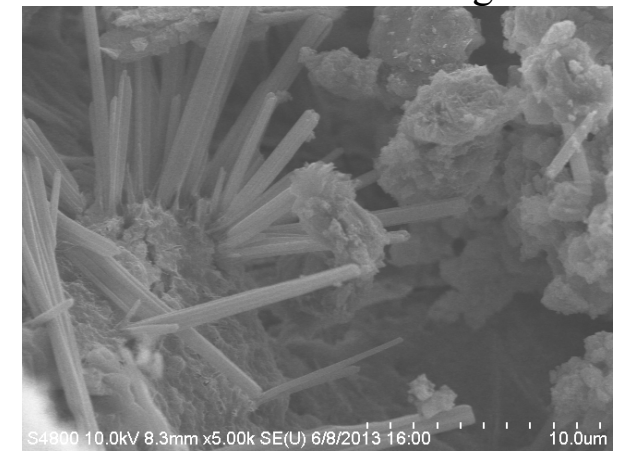

A

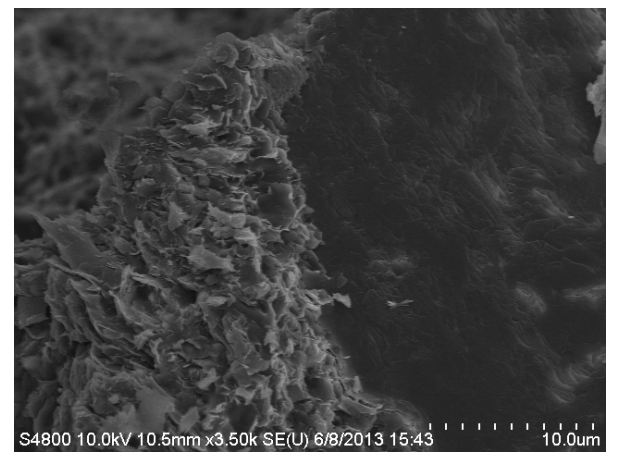

B

Figure 1 SEM micrographs of sample SN2 at 3 days

What could be seen from the SEM micrograph of figure 1A was that the internal structure of sample SN2 of age 3 days was relatively denser, a large amount of acicular ettringite generated with floccules 
gels and that could become the growth core of hydration products. The reason was the amount of sodium hydroxide which produced from sodium silicate hydrolysis increased the liquid phase alkalinity when $\mathrm{Na}_{2} \mathrm{SiO}_{3}$ was used as the activator and destroyed the surface structure of steel slag vitreous. Thus $\mathrm{OH}^{-}$ions made alumina-oxygen bond, silicon-oxygen bond, silicon-aluminum-oxygen bond in slag structure break down. That accelerated the ions of $\mathrm{Ca}^{2+}, \mathrm{Al}^{3+}, \mathrm{SiO}_{4}{ }^{4-}$ to go into the solution and speed up the hydration of the tricalcium silicate and dicalcium silicate. Therefore the cement strength was improved with the formation of C-S-H gel and crystal AFt.

A better bonding degree between cement and aggregate could be seen in the SEM micrograph of figure 1B. A large numbers of floccules hydrated calcium silicate gel were generated accompanied by the cement hydration. The short acicular ettringite and the gel overlapped each other and the pore size of cement stone reduced, hydration products filled in it and made the gel texture relatively denser which improved the strength of cementitious materials.

\section{Conclusions}

The setting time of composite Portland cement gradually shortened with the increase of specific surface area of steel slag when the composite ratio of slag and steel slag was fixed, and the mortar strength in each age increased thereupon. The expansion ratio of composite Portland cement increased with the increase of steel slag composite ratio, the setting time prolonged and the mortar strengths in each age were gradually declined.

The early strength could be improved effectively if the right amount of activators was added in cement. When $2 \%$ sodium silicate was incorporated, the $3 \mathrm{~d}$ flexural strength could be $4.5 \mathrm{MPa}$ and the compressive strength could be $19.2 \mathrm{MPa}$.

The composite Portland cement of grade 42.5R was successfully prepared by using slag and steel slag with some of Portland cement and activator. Its performance could meet Chinese standard titled Common Portland Cement (GB 175-2007) while waste residues could be recycled and the cement production cost could be greatly reduced. The specific ratio of the composite cement was: steel slag $35 \%$, slag $15 \%$, Portland cement $48 \%$, and activator $2 \%$.

\section{Acknowledgements}

The writers would like to acknowledge the support of the National Natural Science Foundation of China under grant 51078241 and China Building Materials Federation under grant 2013-M3-8. The assistance of Hang Li, who completed the experiments referenced in this work, is acknowledged. Finally, the writers would also like to acknowledge the teachers support provided by the inorganic non-metallic materials laboratory.

\section{Reference:}

[1] Shenjin Wang, Jinggen Liu, Shouzhi Zhang, 2011. Industrial wastes applying in blend cement(in Chinese). Concrete, 9, 62-67.

[2] Ming Zhu, Shuguang Hu, Qingjun Ding, 2005. Investigation on applying steel slag to cement based materials(in Chinese). Journal of Wuhan University of Technology, 6, 48-51.

[3] Yifeng Guo, Ping Chen, Yang Ming, et al. 2011. Preparation and optimization of more admixture eco-cement(in Chinese). Bulletin of The Chinese Ceramic Society, 3, 683-687.

[4] Huisheng Shi, Kunsheng Huang, Kai Wu, et al. 2011. Research advance on activation and mechanism of steel slag activity(in Chinese). Fly Ash Comprehensive Utilization, 1, 48-53.

[5] Bakharev T., Sanjayan J. G., Cheng Y. B., 2002. Sulfate attack on alkali-activated slag concrete. Cement and Concrete Research, 32, 211-216. 
[6] Weijun Tang, Zhongxing Ren, Jianhui Zhu, et al. 2007. Study on activation of micro-powder mixture of granulated blast furnace slag and steel slag(in Chinese). Concrete, 12, 65-68. 